\title{
Antibiotic prophylaxis in antenatal nonrefluxing hydronephrosis, megaureter and ureterocele
}

\author{
Marco Castagnetti, Marcello Cimador, Ciro Esposito and Waifro Rigamonti
}

\begin{abstract}
Observation is a conservative management option in infants with nonrefluxing hydronephrosis, primary nonrefluxing megaureter and ureterocele diagnosed postnatally following antenatal detection of hydronephrosis. Antibiotic prophylaxis might be a sensible regimen under these circumstances to prevent UTI in this population who are potentially at increased risk. However, studies examining the efficacy of prophylactic antibiotics are sparse in this setting. For each condition, prophylactic policies seem extremely variable, and UTI rates vary widely with comparable rates reported between patients followed on and off antibiotics. Overall, antibiotic prophylaxis seems unnecessary in patients with isolated low-grade hydronephrosis. Patients with high-grade nonrefluxing hydronephrosis seem at increased risk of UTI, with risk further increasing in patients with associated ureteral dilatation (hydroureteronephrosis) irrespective of the presence of a ureterocele. Obstruction might be an additional independent risk factor, but the diagnosis of obstruction is often possible only in retrospect. The data available suggest that infants are the most at risk of UTI during the first 6 months of life, particularly if they undergo catheterization during workup examinations. Thus, antibiotic prophylaxis might be prudent during the first 6-12 months of life in patients with high-grade hydronephrosis and hydroureteronephrosis with or without ureterocele, and particularly before completion of the diagnostic workup. Paediatric urologists are urged to embark on controlled trials to compare patients followed with and without antibiotic prophylaxis.
\end{abstract}

Castagnetti, M. et al. Nat. Rev. Urol. advance online publication 8 May 2012; doi:10.1038/nrurol.2012.89

\section{Introduction}

Antenatal hydronephrosis-defined as a dilation of the foetal renal collecting system on prenatal ultrasonography (Figure 1) - is detected in approximately $1-5 \%$ of all pregnancies. ${ }^{1-4}$ Representing approximately $30 \%$ of all congenital defects detected on antenatal scans, hydronephrosis is the most common prenatally diagnosed anomaly. ${ }^{5,6}$ A variety of urological conditions can present with antenatal hydronephrosis, and a differential diagnosis can usually be made only after postnatal assessment. ${ }^{7}$ The most common postnatal diagnoses include primary vesicoureteral reflux (VUR) in 10-20\% of cases, nonrefluxing hydronephrosis (probably caused by ureteropelvic junction obstruction) in $10-30 \%$ of cases (Figure 2), nonrefluxing hydroureteronephrosis (also known as primary nonrefluxing megaureter [PNRM]) in $5-10 \%$ of cases (Figure 3 ) and ureterocele in $5 \%$ of cases (Figure 4). ${ }^{7}$ Unlike VUR, the last three conditions can be classified as primarily nonrefluxing dilatations and are the subject of this Review.

In the past 20 years, natural history series have shown that in many infants with nonrefluxing hydronephrosis and PNRM, the dilatation is only transient and tends to improve spontaneously over time without causing any clinical complications. ${ }^{8-12}$ Surgery is required only in patients with symptoms (mainly recurrent febrile

Competing interests

The authors declare no competing interests.
UTI and flank pain), decreased differential renal function at presentation, worsening dilatation or differential renal function during follow-up, which equates to $20 \%$ of patients with nonrefluxing hydronephrosis and $10 \%$ of those with PNMR..$^{8-12}$ Thus, observation has become an accepted management option, at least initially, for patients with these conditions. More recently, nonoperative management has also been proposed as an initial approach in selected patients with ureterocele. ${ }^{13}$

In principle, administration of antibiotic prophylactic drugs is a sensible measure for preventing UTI during observation in patients with a prenatally detected upper urinary tract dilatation whose condition has been confirmed postnatally. ${ }^{14}$ Antibiotic prophylaxis might be particularly appropriate in patients younger than 1 year of age as in this age group UTI are more difficult to diagnose, can develop quickly, can be particularly severe and are likely to cause renal injury and recur. ${ }^{14}$ Nevertheless, although several studies (including randomized clinical trials) have assessed the role of antibiotic prophylaxis in patients with primary VUR, ${ }^{15-17}$ very few studies have specifically focused on the role of antibiotic prophylaxis in patients with nonrefluxing upper urinary tract dilatation or ureterocele. ${ }^{18-22}$ Furthermore, the role of antibiotic prophylaxis in treating patients with primary VUR remains under scrutiny. ${ }^{15,16}$ Indeed, several metaanalyses of recent trials showed the ineffectiveness of antibiotic prophylaxis in preventing UTI recurrence, and
Section of Paediatric Urology, Urology Unit, Department of Oncological and Surgical Sciences, University Hospital of Padua, Monoblocco Ospedaliero, Via Giustiniani 2, 35128 Padua, Italy (M. Castagnetti, W. Rigamonti). Department of

Paediatric Surgery, University of Palermo, Via Alfonso Giordano 3 , 90100 Palermo, Italy

(M. Cimador). Department of Paediatrics, Federico II University of Naples, Via Pansini 5, 80131 Naples, Italy (C. Esposito).

Correspondence to: M. Castagnetti marcocastagnetti@ hotmail.com 


\section{Key points}

- Evidence supporting the use of antibiotic prophylaxis to prevent UTI in infants with nonrefluxing upper tract dilatations or ureterocele is inconclusive

- Reported infection rates vary widely and are comparable in patients receiving prophylaxis and those who are not

- The prescription of antibiotic prophylaxis for UTI seems to be influenced by the local medical standards, physician experience and the likelihood of prescribing postnatal investigations

- Antibiotic prophylaxis can be avoided in patients with low-grade hydronephrosis and no ureteral dilatation

- Patients with high grades of hydronephrosis are at increased risk of UTI; a dilated ureter increases the risk, whereas the presence of ureterocele does not

- Infants are most at risk in the first 6 months of life, and catheterization performed during work-up might trigger the infection

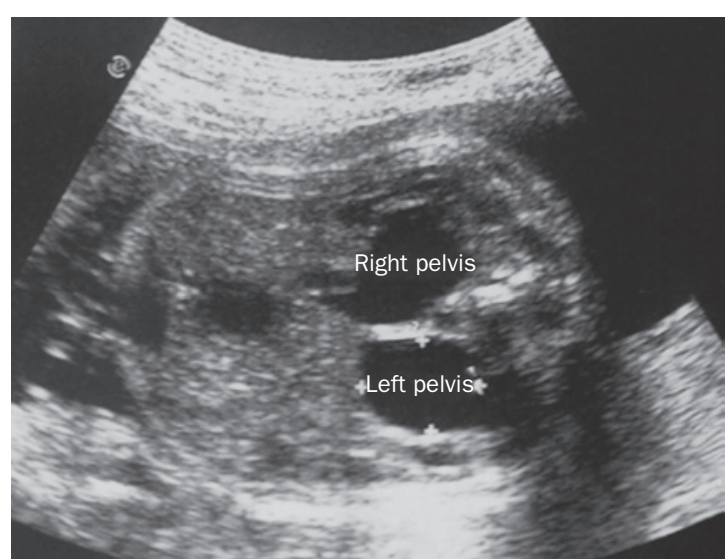

Figure 1 | Antenatal ultrasonograph showing bilateral hydronephrosis.

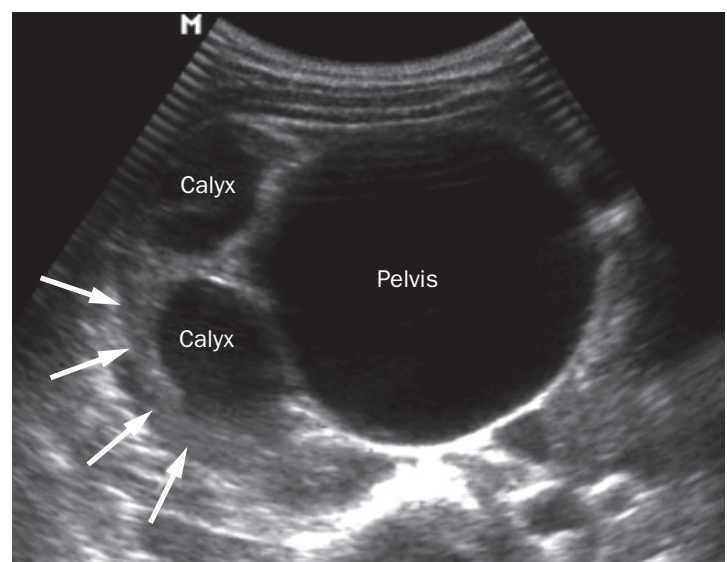

Figure 2 | Postnatal ultrasonograph of hydronephrosis on the transverse plane. The infant has a dilated renal pelvis and calyces. The arrows point to the renal parenchyma.

concern mounts regarding its potential drawbacks. ${ }^{15-17}$ For example, antibiotic prophylaxis might favour selection of antibiotic-resistant bacterial strains, is poorly accepted by parents and increases the health-care burden (Box 1). ${ }^{23,24}$

In this Review, we critically assess the available data on the role of antibiotic prophylaxis in the conservative management of hydronephrosis, PNRM and ureterocele. For each condition, we assess the antibiotic prophylaxis policy reported in surveys of physician preferences, statements of scientific societies and major natural history series. We also evaluate the results of controlled trials and uncontrolled series. Finally, we assess the time of onset of UTI and summarize the possible risk factors for UTI.

\section{Antibiotic prophylactic regimens and UTI rates Nonrefluxing hydronephrosis}

General considerations

Assessing the role of antibiotic prophylaxis in nonrefluxing hydronephrosis presents two major issues. First, there is no consensus on the criteria, such as the degree of pelvic dilatation, to define a clinically significant hydronephrosis. ${ }^{25,26}$ Second, there is no standard postnatal assessment protocol in patients with the condition. Indeed, currently there is no agreement on several aspects of postnatal assessment, including the need and timing for postnatal ultrasonography, voiding cystourethrography (VCUG) and renal scintigraphy. ${ }^{25,26}$ Many physicians tend either to perform ultrasonography (with or without renal nuclear scan) or to rely on prenatal results to plan postnatal treatment; many physicians also avoid invasive tests such as voiding cystourethrography. ${ }^{25,26}$ This approach is based on the assumption that, in the absence of ureteral dilatation, VUR occurs in fewer than $15 \%$ of patients and, when present, is usually low grade and tends to resolve spontaneously without causing UTI. ${ }^{27}$ Most studies consistently assess the risk of UTI and the need for antibiotic prophylactic treatment in patients with hydronephrosis, irrespective of the presence of VUR. ${ }^{28,29}$ This choice is clinically meaningful, but impairs an accurate evaluation of the specific role of antibiotic prophylaxis in the individual conditions.

\section{Recommended and reported practice}

A 2004 survey of North American and European paediatric urologists concerning the prescription of prophylactic antibiotics for antenatal hydronephrosis revealed considerable variability in practice. ${ }^{26}$ The authors found that increased prophylactic antibiotic use paralleled the severity of the condition. Fewer than $5 \%$ of paediatric urologists recommended antibiotic prophylactics in patients with low-grade hydronephrosis (defined as an anteroposterior diameter of the renal pelvis on the transverse plane $<4 \mathrm{~mm}$ or grade I hydronephrosis according to the Society for Fetal Urology [SFU] criteria). ${ }^{7}$ At the opposite end of the spectrum, more than $65 \%$ of urologists recommended antibiotic prophylaxis in severe cases (defined as an anteroposterior diameter of the renal pelvis $>10 \mathrm{~mm}$ or SFU grade IV hydronephrosis). Furthermore, antibiotic use was considerably different between the two continents and seemed to be inversely correlated to the likelihood that the urologist would perform postnatal investigations. Specifically, paediatric urologists from North America were less likely than European urologists to prescribe postnatal investigations and more likely to prescribe antibiotic prophylactics. Notably, the choice to prescribe antibiotics also seemed to be influenced by the physician's experience: $46 \%$ of paediatric urologists in practice for $>15$ years 

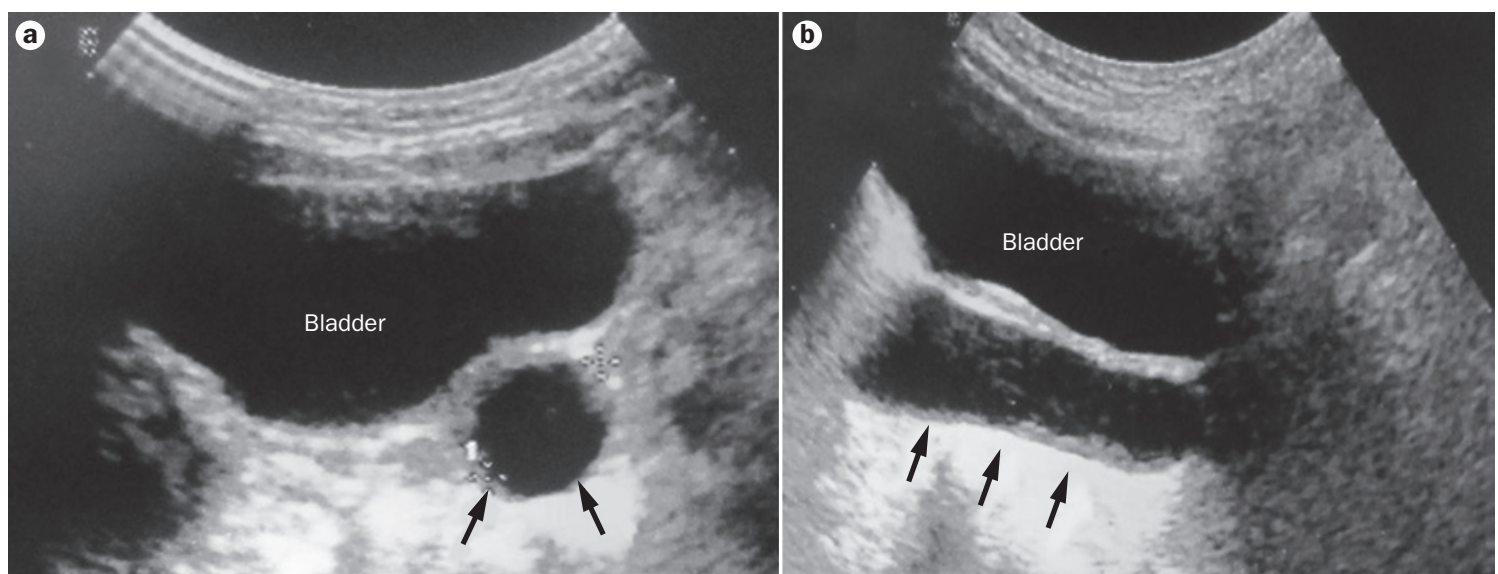

Figure 3 | Ultrasonograph of megaureter. a | Coronal plane view. b | Sagittal plane view. The arrows point to a dilated retrovesical ureter.

recommended antibiotic prophylaxis, whereas $68 \%$ of those in practice for $<15$ years recommended antibiotics $(P<0.05)$. A different study noted no major differences in practice between paediatric urologists and nephrologists from the same cultural region (French-speaking countries) in managing antenatal hydronephrosis. ${ }^{25}$ Finally, a third study of US paediatricians found about half of those questioned prescribed antibiotic prophylactics for antenatal hydronephrosis. ${ }^{30}$ Of the paediatricians who did not prescribe antibiotics, about half referred the patient to a specialist immediately, leaving the latter to decide further management steps. ${ }^{30}$ Indeed, paediatricians without readily available specialist consultation were most likely to prescribe antibiotic prophylactics. ${ }^{30}$ Notably, even those US paediatricians who thought that the published data on antibiotic prophylaxis were ambiguous and inconclusive still had threefold to sixfold greater odds of prescribing antibiotics than those declaring to have not read the published data. ${ }^{30}$

In their 2005 consensus statement on the evaluation and management of antenatal hydronephrosis, the SFU recommend the use of antibiotic prophylactics in patients with high-grade hydronephrosis (SFU grade III or IV) or obstructive drainage patterns. ${ }^{7}$ However, the statement also emphasizes that no prospective randomized trials are available to support the recommendations that compare antibiotic use against no antibiotics in children with these conditions; the efficacy of antibiotic prophylaxis has not been conclusively proven.

Of the major series on the natural history of congenital hydronephrosis and the trials comparing surgical intervention with observation, some do not define the use of antibiotic prophylactics in patients managed conservatively. ${ }^{31,32}$ By contrast, other studies have recommended the administration of antibiotics in the first year of life, or until there is significant improvement in hydronephrosis. ${ }^{8,9}$

\section{Clinical studies}

To the best of our knowledge, only one retrospective study has provided comparative data on the UTI rates in patients with pelviureteric junction obstruction receiving prophylactic antibiotics with those patients who are not. No difference was observed in the prevalence of UTI between patients who did and did not receive antibiotics; ${ }^{8}$ UTI occurred in five of 37 patients (14\%) and
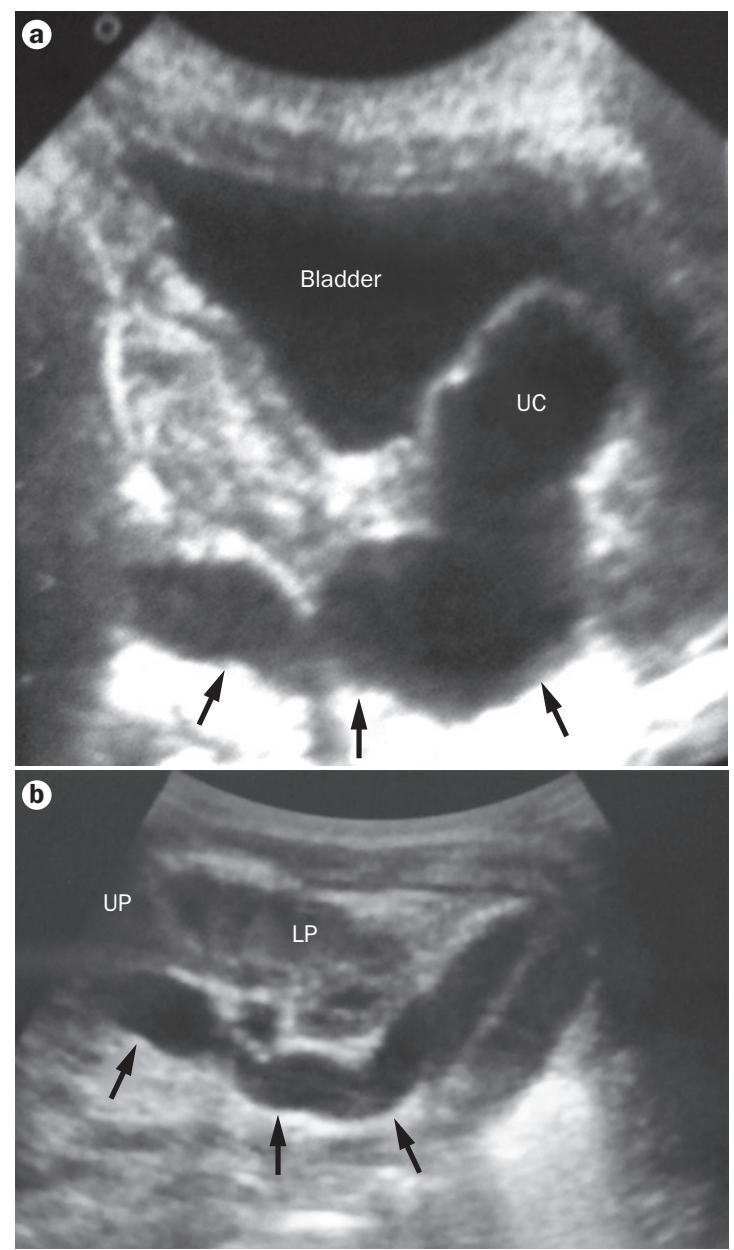

Figure 4 | Ultrasonograph showing a ureterocele.

a | Ureterocele within the bladder. b | Ureterocele in a patient with upper pole hydroureteronephrosis. The arrows point to a dilated ureter. Abbreviations: LP, lower pole; UC, ureterocele; UP, upper pole. 
Box $1 \mid$ Antibiotic exposure in early life

The use of antibiotics in infancy has been associated with drawbacks and complications, some of which are associated with chronic use during prophylactic treatment and some with short-term exposure. Adverse effects (such as nausea, vomiting and abdominal pain) are estimated to occur in $10.4 \%$ of infant patients on antibiotic prophylaxis for VUR, and are the reason for discontinuing treatment in $8.2 \%$ of these patients. ${ }^{50} \mathrm{~A}$ notable drawback of antibiotic use is the development of resistance, which is a global problem. One study found that children exposed to antibiotics for more than 4 weeks in a 6-month period were 23 times more likely to have an E. coli urinary isolate that was resistant to trimethoprim-sulphamethoxazole than children who had not received antibiotics. ${ }^{51}$ Poor compliance is another relevant issue. One study found that only $17 \%$ of children on antibiotic prophylaxis for VUR actually had a urine sample positive for antibiotics. ${ }^{52} \mathrm{An}$ analysis of over 35,000 patients with VUR noted that only 1 of 10 was $100 \%$ compliant with antimicrobial prophylaxis. ${ }^{53}$ Patient noncompliance can favour the development of drug resistance and can result in breakthrough UTI as well as the increased need for hospital admission, additional physician visits, testing and extra medications-all of which result in increases in the cost of management. ${ }^{54,55}$ Finally, antibiotic exposure during the first year of life is associated with an increased risk of developing atopic diseases including eczema, wheeze, asthma and allergy later in life. ${ }^{56}$ The underlying mechanism has been summarized in the so-called hygiene hypothesis, which suggests that growing up in an increasingly hygienic environment with reduced microbial exposure might increase atopic (T-helper-2) immune responses and, therefore, the development of asthma and other allergic conditions. ${ }^{57}$

Abbreviation: VUR, vesicoureteral reflux.

three of 16 (19\%) patients, respectively. Unfortunately, the authors of this study did not disclose the prophylactic regimen used or the characteristics of the patients receiving antibiotic prophylaxis. The latter in particular is an important limitation of the study because it remains unclear whether the administration of prophylaxis was reserved for patients with moderate degrees of dilatation, which might limit the validity of these results.

Several uncontrolled series assessed the risk of UTI in patients with antenatally detected nonrefluxing hydronephrosis observed while either on or off antibiotic prophylaxis (Table 1). In patients not prescribed antibiotics, the prevalence of UTI ranged between $2 \%$ and $31 \%$. Only one series reported the outcomes of patients with antenatally detected hydronephrosis receiving prophylactic antibiotics. ${ }^{21}$ In that study, the prevalence of UTI was $28 \%$, comparable to the highest prevalence in the former series of patients not receiving antibiotics.

\section{Primary nonrefluxing megaureter \\ General considerations}

The postnatal management of PNRM is less controversial than that of hydronephrosis. Indeed, if a dilated retrovesical ureter is seen on prenatal or postnatal ultrasonography of a patient with an antenatal hydronephrosis, the need for further investigation is generally agreed upon. ${ }^{33}$ These investigations include VCUG to rule out VUR.

\section{Recommended and reported practice}

We are not aware of any surveys of physician preferences regarding the use of prophylactic antibiotics in the conservative management of patients with PNRM. As for hydronephrosis, the 2005 consensus statement of the SFU recommended the use of antibiotic prophylaxis in patients with PNRM. ${ }^{7}$
Of the major series on the natural history of PNRM reported in the past decade, some do not define the use of antibiotic prophylaxis in patients managed conservatively, ${ }^{34}$ whereas others report inconsistent protocols. For example, McLellan et al. ${ }^{11}$ recommended prophylactic antibiotics for their patients until the ages of 9-12 months by physician preference, whereas Shukla et al. ${ }^{12}$ recommended antibiotic administration until the diagnosis was confirmed in all patients. Furthermore, Shukla et al. ${ }^{12}$ recommended prolonged antibiotic regimens only in selected patients until the ureteral dilatation resolved or demonstrated a trend towards improvement. However, the characteristics of the subgroup receiving prolonged antibiotic prophylactics and the duration of the prolonged antibiotic prophylaxis were not reported.

\section{Clinical studies}

To the best of our knowledge, there are no controlled studies comparing antibiotic prophylaxis with no treatment in patients with PNRM. The reported prevalence of UTI in series of patients with PNRM has a wide range, between $8 \%$ and $46 \%$ (Table 1), without any apparent reasons accounting for these differences. Coelho et al. ${ }^{21}$ reported the only series of patients with antenatally detected PNRM receiving antibiotic prophylactics. In this series, the prevalence of UTI (25\%) was similar to that in the series of patients who did not receive antibiotic prophylaxis (8-46\%).

\section{Ureterocele \\ General considerations}

Ureterocele is a fairly variable clinical condition that can present with nonrefluxing hydroureteronephrosis of the ureter draining into the ureterocele, in either a single or duplex collecting system. ${ }^{35}$ However, ureterocele can also be associated with nonrefluxing hydroureteronephrosis or VUR in any of the ipsilateral or contralateral ureters as well as with bladder outlet obstruction (Figure 5). ${ }^{35}$ Indeed, VUR in this context can be secondary to the bladder outlet obstruction or the distortion of the trigonal anatomy caused by the ureterocele itself.

Postnatal assessment for ureterocele is not controversial and most paediatric urologists agree on the need for a comprehensive assessment that includes ultrasonography, VCUG and renal nuclear scan. ${ }^{36}$ However, there is no consensus on the criteria for selecting patients for conservative management, which might be reasonable in patients without bladder outlet obstruction, good upper tract drainage on renal nuclear scan and absence of or low-grade-associated VUR (Table 2). ${ }^{13,37-40}$ On the basis of these criteria, only a minority (12-27\% of all patients with ureterocele in published series) of patients would be eligible for conservative treatment. ${ }^{13,37,38}$ Regardless, the issue of whether these patients might benefit from antibiotic prophylaxis is also relevant to those who undergo surgery. Postponing early surgical intervention for a few months to await a comprehensive workup and allow the infant to grow is an approach that is increasingly used. ${ }^{41}$ Antibiotic prophylaxis might have an important role in this period between initial diagnosis and primary treatment. 
Table 1 | UTI in series of patients with nonrefluxing hydronephrosis or PNRM*

\begin{tabular}{|c|c|c|c|c|c|c|}
\hline \multirow[t]{2}{*}{ Study } & \multirow[t]{2}{*}{$n$} & \multirow[t]{2}{*}{ Inclusion criteria } & \multirow[t]{2}{*}{ Prophylaxis regimen } & \multirow[t]{2}{*}{ Follow-up } & \multicolumn{2}{|c|}{ Rate of UTI } \\
\hline & & & & & $\begin{array}{l}\text { Patients with } \\
\text { hydronephrosis }\end{array}$ & $\begin{array}{l}\text { Patients } \\
\text { with PNRM }\end{array}$ \\
\hline $\begin{array}{l}\text { Song } \\
\text { et al. }{ }^{18} \\
(2007)\end{array}$ & 93 & $\begin{array}{l}\text { Antenatal hydronephrosis }{ }^{\ddagger} ; \\
\text { severe obstruction on } \\
\text { diuretic renography; no } \\
\text { circumcision }\end{array}$ & No prophylaxis & $\begin{array}{l}12 \text { months after } \\
\text { birth }\end{array}$ & 23/75 (31\%) & 7/18 (39\%) \\
\hline $\begin{array}{l}\text { Lee et al. }{ }^{19} \\
(2008)\end{array}$ & 412 & $\begin{array}{l}\text { Antenatal hydronephrosis\$; } \\
\text { no circumcision }\end{array}$ & No prophylaxis & $\begin{array}{l}12 \text { months after } \\
\text { birth }\end{array}$ & $46 / 351(13 \%)$ & $\begin{array}{l}28 / 61 \\
(46 \%)\end{array}$ \\
\hline $\begin{array}{l}\text { Roth et al. }{ }^{20} \\
(2009)\end{array}$ & 92 & Antenatal hydronephrosis ${ }^{\ddagger}$ & No prophylaxis & $\begin{array}{l}27 \text { months after } \\
\text { birth }\end{array}$ & $1 / 56(2 \%)$ & $3 / 36(8 \%)$ \\
\hline $\begin{array}{l}\text { Islek et al. }{ }^{22} \\
(2011)\end{array}$ & 84 & Antenatal hydronephrosis $\$$ & No prophylaxis & $\begin{array}{l}\text { Median } 18 \\
\text { (12-24) months } \\
\text { after diagnosis }\end{array}$ & $0 / 84(0 \%)$ & NR \\
\hline $\begin{array}{l}\text { Coelho } \\
\text { et al. }{ }^{21} \\
\text { (2008) }\end{array}$ & 61 & $\begin{array}{l}\text { Antenatal hydronephrosis } \$ \text {; } \\
\text { no circumcision }\end{array}$ & $\begin{array}{l}50 \mathrm{mg} \text { cephalexin daily in } \\
\text { the first } 2 \text { months of life, } \\
\text { then } 1-2 \mathrm{mg} \text { per kg of } \\
\text { trimethoprim without any } \\
\text { age limit for discontinuation }\end{array}$ & $\begin{array}{l}\text { Median } \\
24 \text { months after } \\
\text { birth }\end{array}$ & $13 / 53(28 \%)$ & $2 / 8(25 \%)$ \\
\hline
\end{tabular}

*Diagnosed postnatally following antenatal detection of a urinary tract dilatation and followed conservatively either with or without antibiotic prophylaxis.

‡Society for Fetal Urology grade III or IV. \$Any grade. Abbreviations: NR, not reported; PNRM, primary nonrefluxing megaureter.

\section{Recommended and reported practice}

In a recent survey of paediatric urologists regarding the management of duplex-system ureterocele, some $85 \%$ of responders favoured prescribing antibiotic prophylaxis if observation was elected as the initial management strategy. ${ }^{36}$ This approach was still preferred by $71 \%$ of responders even if the patient had a negative VCUG. ${ }^{36}$ This choice did not seem to be influenced by the region where the paediatric urologist was based or their experience (years of practice).

We are unaware of any guideline or recommendation from scientific or medical societies on the use of antibiotic prophylaxis specifically in patients with ureterocele. However, antibiotic prophylactics were consistently recommended in the series of patients with ureterocele managed conservatively, ${ }^{37-40}$ although the recommended regimens are quite variable, particularly with respect to the duration (Table 2).

\section{Clinical studies}

To the best of our knowledge, only one retrospective study has compared the infection rates in patients with antenatally detected ureteroceles treated with and without antibiotic prophylactics. ${ }^{42}$ In this small series, UTI occurred in $53 \%$ of patients overall, including three of seven (43\%) patients who received prophylactic antibiotics and five of eight (62.5\%) patients who did not.

The uncontrolled series of patients with ureterocele who did not receive antibiotic prophylactic treatment in the first year of life report high UTI rates. Two separate Korean studies found UTI in seven of $10(70 \%)$ patients with ureterocele ${ }^{18}$ and 10 of 17 (59\%) patients. ${ }^{19}$ In contrast with these data, UTI occurred in only four of $45(9 \%)$ infants included in series of patients with ureteroceles given antibiotics (Table 2). ${ }^{13,37-40}$ However, these series had strict inclusion criteria and were uncontrolled; the patients included were possibly at low risk of developing UTI and would have fared well without antibiotic prophylaxis. Nevertheless, the reported UTI rates were also quite low in several series of unselected patients diagnosed antenatally who were prescribed antibiotic prophylactics while awaiting surgery. ${ }^{43-47}$ Under these circumstances, the rate of UTI ranged between $0 \%$ and $26 \%$ with a follow-up spanning between the first 3 months and 6 months of age (Table 3). ${ }^{43-47}$ Another study found that the rate of UTI at 6 months of age in 40 patients receiving antibiotic prophylaxis (unspecified regimen) was not statistically different to the rate in 32 patients who underwent early endoscopic decompression of the ureterocele and subsequent antibiotic prophylaxis (unspecified regimen). ${ }^{48}$ Although the study was limited by an arbitrary allocation of patients to either treatment, it suggests that antibiotic prophylaxis alone might be as effective as surgical decompression in patients in the first 6 months of age. Whether the UTI rates would be the same without antibiotic prophylaxis remains unclear.

\section{Timing of UTI onset}

Although no study reports the timing of UTI onset separately for each condition, all the series do report that UTI onset is very early irrespective of the condition. Song et al. ${ }^{18}$ reported the mean age at onset of UTI as 2.6 months in infants with obstructive hydronephrosis, with UTI developing before 6 months of age in 93\% of patients. Similarly, Lee et al. ${ }^{19}$ report that the first UTI occurred at an average age of $4.1 \pm 2.7$ months, and UTI developed before 6 months of age in $84 \%$ of patients. Finally, Roth et al. ${ }^{20}$ reported an average patient age at the occurrence of UTI of 6.1 months (with a range of 1-11 months).

Notably, infection developed soon after a workup investigation that required catheterization in eight of the 83 patients who developed UTI in the series by Lee et $a l .{ }^{19}$ and two of the four who developed UTI in the 


\section{REVIEWS}
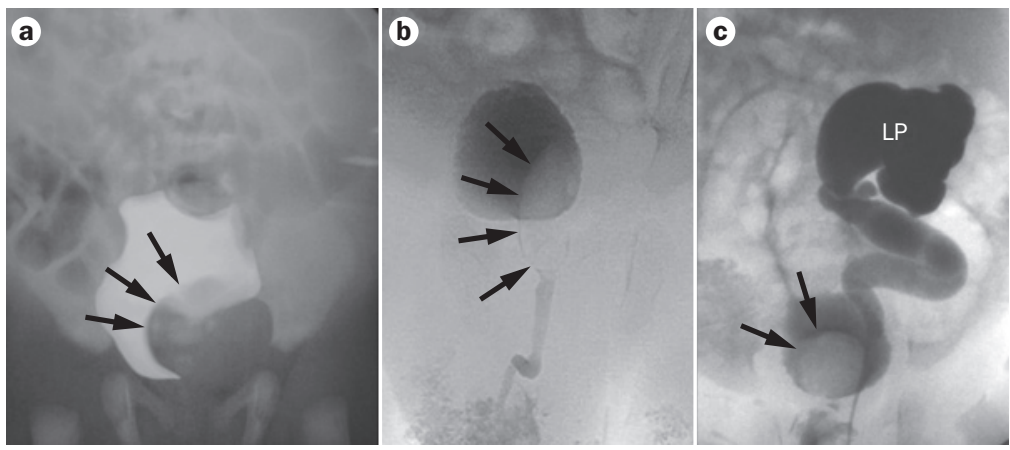

Figure $\mathbf{5}$ | Voiding cystourethrograph showing a ureterocele. a | The ureterocele is a filling defect within the bladder during the filling phase. $\mathbf{b} \mid$ The ureterocele is encroaching on the posterior urethra during micturition. No vesicoureteral reflux is visible on these films. $\mathbf{c}$ | The ureterocele with associated ipsilateral LP vesicoureteral reflux. The arrows point to the ureterocele. Abbreviation: LP, lower pole.

series by Roth et al. ${ }^{20}$ Although excluding these patients did not change the overall timing of onset, this observation might deserve clinical consideration. If UTI is triggered by invasive procedures performed during the workup such as catheterization, antibiotic prophylaxis might be effective if administered in the period before completion of the diagnostic workup, or even during the single investigations requiring catheterization.

\section{Risk factors for UTI}

A number of factors might influence the risk of developing UTI in patients with hydronephrosis, PNRM and ureterocele, although few studies report these. Again, we could not identify studies assessing the risk factors for UTI in each condition separately.

In general, patient sex and circumcision status are the most obvious risk factors for UTI. However, in all but one study of patients with nonrefluxing upper urinary tract dilatation or ureterocele, sex was not associated with an increased risk of UTI. ${ }^{18-22}$ The only study reporting a correlation between female sex and UTI included in the multivariate analysis a significant number of patients with congenital hydronephrosis caused by primary VUR, ${ }^{21}$ which limits the validity of the study. Only one study assessed the influence of circumcision status on the development of UTI; no difference was reported in the UTI rate between circumcised and uncircumcised boys. ${ }^{20}$

Lee et al..$^{19}$ investigated the risk of UTI in relation to the degree of hydronephrosis, and observed that high grades (SFU grade III and IV) of hydronephrosis were significantly associated with an increased risk of UTI. UTI occurred in $4 \%$ of patients with grade I hydronephrosis compared with $40 \%$ of those with grade IV $(P<0.001)$, which corresponded to an almost 17 -fold increased risk. ${ }^{19}$ This variable was also significant on multivariate analysis. ${ }^{19}$ The counterpart of this observation is that lowgrade hydronephrosis is associated with a reduced risk of UTI. In line with this observation, a study of 223 patients ( $\leq 12$ months of age) with an anteroposterior diameter of the renal pelvis on the transverse plane of $10-15 \mathrm{~mm}$ and 230 healthy controls without evidence of any urinary tract dilatation reported infection rates of $3.6 \%$ and $2.5 \%$, respectively. ${ }^{29}$ In another study by the same authors, the
UTI rate reached $7 \%$ in patients with severe hydronephrosis (defined as an anteroposterior diameter of the renal pelvis on the transverse plane $>15 \mathrm{~mm}){ }^{49}$

Lee et al. ${ }^{19}$ also reported that the presence of obstructive uropathy is an independent risk factor. However, the authors defined obstructive uropathy as an obstructive drainage pattern on dynamic scintigraphy, or a negative clinical course with worsening of the dilatation or renal function loss over subsequent follow-up renal nuclear scans. The latter implies that the diagnosis of obstruction in a few patients is possible only in retrospect considering multiple investigations, which is clinically unpractical for deciding whether or not to commence antibiotic prophylaxis at presentation.

Additional independent risk factors have also been identified. For example, the presence of a hydroureter in addition to high-grade hydronephrosis seems to be an independent risk factor for UTI..$^{18,19}$ In patients with hydroureteronephrosis the simultaneous presence of a ureterocele did not appear to be an independent risk factor for UTI..$^{18,19}$ Thus, the presence of hydroureteronephrosis is more important than the underlying condition for predicting the likelihood of UTI.

\section{Conclusions}

The few reports summarized in this Review reveal much variability in the policies concerning the administration of antibiotic prophylaxis in infants with congenital nonrefluxing hydronephrosis, PNRM and ureterocele. Unexpectedly, local medical standards and physician experience might influence the decision to prescribe antibiotics. Moreover, the likelihood that a patient is prescribed antibiotic prophylactics seems to be inversely correlated with the likelihood they undergo postnatal investigations. Furthermore, it seems that some physicians, although aware that evidence regarding the role of antibiotic prophylaxis is inconclusive, still prefer to prescribe the treatment. Multiple factors might account for such a decision, including the preference to err on the side of caution or for medicolegal reasons. ${ }^{30}$

The risk of UTI seems to be low in patients with low-grade isolated hydronephrosis (namely no ureteral dilatation), SFU grade I or II hydronephrosis or an anteroposterior diameter of the renal pelvis $<15 \mathrm{~mm}$. In these patients, the risk of developing a UTI does not differ from that of the general population and antibiotic prophylactics are not necessary.

However, risk of UTI seems to increase with increasing severity of hydronephrosis. Increased urinary stasis in a severely dilated urinary system might account for this observation. Associated ureteral dilatation, namely presence of hydroureteronephrosis, seems to further increase the risk of UTI, possibly because the extension of the severely dilated urinary reservoir to the bladder makes urinary contamination easier. Interestingly, the presence of ureterocele does not seem to be an independent risk factor, as the risk of UTI in patients with hydroureteronephrosis and ureterocele is comparable to that in patients with hydroureteronephrosis alone. An additional independent risk factor for infections might be the presence of 
Table 2 | Antibiotic prophylaxis in patients with ureterocele managed conservatively

\begin{tabular}{|c|c|c|c|c|c|}
\hline Study & $n$ & Inclusion criteria & Antibiotic prophylaxis & Follow-up (years) & UTI rate (\%) \\
\hline $\begin{array}{l}\text { Shankar } \\
\text { et al. }{ }^{13}(2001)\end{array}$ & $\begin{array}{l}14 \\
\text { of } 52\end{array}$ & $\begin{array}{l}\text { Asymptomatic; lower pole VUR; no lower } \\
\text { pole nonrefluxing hydronephrosis; no } \\
\text { BOO; upper pole function }<10 \%\end{array}$ & $\begin{array}{l}\text { Until completion of } \\
\text { toilet training or } \\
5 \text { years of age in case } \\
\text { of persisting VUR }\end{array}$ & $\begin{array}{l}\text { Median, 8; range, } \\
1.6-12.8\end{array}$ & 0 \\
\hline $\begin{array}{l}\text { Merguerian } \\
\text { et al. }{ }^{37}(2003)\end{array}$ & $\begin{array}{l}10 \\
\text { of } 60\end{array}$ & $\begin{array}{l}\text { Minor upper pole dilatation; no evidence } \\
\text { of obstruction on renal scan }\end{array}$ & NR & $\begin{array}{l}\text { Mean, } \\
4.95 \pm 2.08^{\ddagger}\end{array}$ & 0 \\
\hline $\begin{array}{l}\text { Coplen and } \\
\text { Austin } \\
\text { (2004) }\end{array}$ & $\begin{array}{l}4 \\
\text { of } 34\end{array}$ & $\begin{array}{l}\text { Multicystic dysplasia in the ureterocele } \\
\text { moiety; no ureteric dilatation; VUR in } \\
\text { other moieties; no BOO }\end{array}$ & $\begin{array}{l}\text { Until resolution of VUR } \\
\text { or completion of toilet } \\
\text { training }\end{array}$ & $\begin{array}{l}\text { Mean, 3; range, } \\
1.2-4.5\end{array}$ & $\begin{array}{l}25(1 \\
\text { patient) }\end{array}$ \\
\hline $\begin{array}{l}\text { Han et al. }{ }^{39} \\
(2005)\end{array}$ & $11 *$ & $\begin{array}{l}\text { Good or no function in the ureterocele } \\
\text { moiety; no evidence of high-grade } \\
\text { obstruction on renal nuclear scan }\end{array}$ & $\begin{array}{l}\text { Until completion of } \\
\text { toilet training }\end{array}$ & $\begin{array}{l}\text { Median, 3.4; range } \\
\text { 1-8 }\end{array}$ & $\begin{array}{l}27(3 \\
\text { patients) }\end{array}$ \\
\hline $\begin{array}{l}\text { Di Renna and } \\
\text { Leonard }{ }^{40} \\
(2006)\end{array}$ & $6 *$ & $\begin{array}{l}\text { Asymptomatic; lower pole VUR; no lower } \\
\text { pole nonrefluxing hydronephrosis; no } \\
\text { BOO; upper pole function }<10 \% \text { or }>10 \% \\
\text { with no obstruction }\end{array}$ & $\begin{array}{l}\text { For a mean of } \\
1.5 \text { years (range } \\
2 \text { months to } 4 \text { years) }\end{array}$ & $\begin{array}{l}\text { Median, 5; range, } \\
1-11\end{array}$ & 0 \\
\hline
\end{tabular}

*Total population size NR. ^Range not reported. \$̊ Half-life < $30 \mathrm{~min}$. Abbreviations: BOO, bladder outlet obstruction; NR, not reported; VUR, vesicoureteral reflux.

Table 3 | UTI rates in patients with ureterocele treated with or without antibiotics before surgical decompression

\begin{tabular}{|c|c|c|c|c|}
\hline Study & $n$ & Prophylaxis & Age at surgery (months) & UTI rate (\%) \\
\hline $\begin{array}{l}\text { Decter et al. }{ }^{43} \\
\text { (2001) }\end{array}$ & 27 & $25 \mathrm{mg}$ amoxicillin daily from birth & NR & 0 \\
\hline $\begin{array}{l}\text { Husmann et al. }{ }^{44} \\
\text { (1995) }\end{array}$ & 33 & $\begin{array}{l}25 \mathrm{mg} \text { per kg birth weight amoxicillin or cefaclor daily } \\
\text { from birth }\end{array}$ & 3 & 9 (3 patients) \\
\hline $\begin{array}{l}\text { Shekarriz et al. }{ }^{45} \\
\text { (1999) }\end{array}$ & 25 & No uniform policy & 3 & 12 (3 patients)* \\
\hline $\begin{array}{l}\text { Upadhyay et al. }{ }^{46} \\
\text { (2002) }\end{array}$ & 40 & $\begin{array}{l}2 \mathrm{mg} \text { per } \mathrm{kg} \text { birth weight trimethoprim or trimethoprim- } \\
\text { sulfamethoxazole daily from } 6 \text { weeks of age }\end{array}$ & 6 & 12 (5 patients) \\
\hline $\begin{array}{l}\text { Chertin et al. }{ }^{47} \\
(2005)\end{array}$ & 35 & Regimen NR & 4 & 26 (9 patients) \\
\hline
\end{tabular}

obstruction, although the definition of obstruction remains unclear because the presence of obstruction can sometimes only be diagnosed in retrospect based on the clinical course (such as the development of symptoms or a functional loss during follow-up). Patient sex and circumcision status do not appear to influence the rate or likelihood of UTI. In terms of timing of UTI onset, the first 6 months of life are the most risky period. Furthermore, workup procedures requiring catheterization might trigger infection.

Overall, the possible increased risk of UTI in patients with nonrefluxing upper urinary tract dilatation does not warrant the use of antibiotic prophylaxis. The evidence regarding the risk of UTI in patients treated with prophylactic antibiotics and those left untreated are inconclusive. The range of reported infection rates is very wide, with overlap in the UTI rates of patients receiving prophylaxis and those not. Of the very few series available, at least on $\mathrm{e}^{21}$ reported a very low UTI rate in patients left untreated, another study reported a rate of UTI in patients receiving treatment comparable to that of patients left untreated. ${ }^{18-20}$

In the absence of reliable, reproducible data, antibiotic prophylactics should always be prescribed to neonates and infants undergoing investigations that require catheterization. Additionally, antibiotic prophylaxis might be prudent in patients with high-grade hydronephrosis (SFU grade III and IV), as well as in patients with hydroureteronephrosis with or without ureterocele. Antibiotics might be most effective if given in the first 6-12 months of life, or until after completion of the baseline workup. Nevertheless, this Review emphasizes that the evidence supporting this practise is weak and inconclusive. Therefore, paediatric urologists should be aware of the limits of antibiotic prophylaxis for UTI in these patients, and are urged to embark on controlled trials to compare patients treated with antibiotics with those left untreated, and to compare different regimens.

Review criteria
A MEDLINE/PubMed search was performed using the
keywords "hydronephrosis", "ureteropelvic junction
obstruction", "hydroureteronephrosis", "megaureter", and
"ureterocele". The search was limited to papers published
in English between January 1, 1990 and February 29, 2012
and to human studies in children aged 0-18 years. Only full-
text papers were considered. Selection of papers relevant
to the topic of this Review was not aimed to be systematic,
and inclusion of most recent literature was favoured. The
reference lists of selected papers were also searched for
additional relevant literature.


1. Blyth, B., Snyder, H. M. \& Duckett, J. W. Antenatal diagnosis and subsequent management of hydronephrosis. J. Urol. 149, 693-698 (1993).

2. Gunn, T. R., Mora, J. D. \& Pease, P. Antenatal diagnosis of urinary tract abnormalities by ultrasonography after 28 weeks' gestation: incidence and outcome. Am. J. Obstet. Gynecol. 172, 479-486 (1995).

3. Livera, L. N., Brookfield, D. S., Egginton, J. A. \& Hawnaur, J. M. Antenatal ultrasonography to detect fetal renal abnormalities: a prospective screening programme. BMJ 298, 1421-1423 (1989).

4. Sairam, S., Al-Habib, A., Sasson, S. \& Thilaganathan, B. Natural history of fetal hydronephrosis diagnosed on mid-trimester ultrasound. Ultrasound Obstet. Gynecol. 17, 191-196 (2001).

5. Queisser-Luft, A., Stolz, G., Wiesel, A., Schlaefer, K. \& Spranger, J. Malformations in newborn: results based on 30,940 infants and fetuses from the Mainz congenital birth defect monitoring system (1990-1998). Arch. Gynecol. Obstet. 266, 163-167 (2002).

6. Wiesel, A., Queisser-Luft, A., Clementi, M., Bianca, S. \& Stoll, C. EUROSCAN Study Group. Prenatal detection of congenital renal malformations by fetal ultrasonographic examination: an analysis of 709,030 births in 12 European countries. Eur. J. Med. Genet. 48, 131-144 (2005).

7. Nguyen, H. T. et al. The Society for Fetal Urology consensus statement on the evaluation and management of antenatal hydronephrosis. J. Pediatr. Urol. 6, 212-231 (2010).

8. Madden, N. P. et al. Antenatally detected pelviureteric junction obstruction: is nonoperation safe? Br. J. Urol. 68, 305-310 (1991).

9. Dhillon, H. K. Prenatally diagnosed hydronephrosis: the Great Ormond Street experience. Br. J. Urol. 81, 39-44 (1998).

10. Ulman, I., Jayanthi, V. R. \& Koff, S. A. The longterm followup of newborns with severe unilateral hydronephrosis initially treated nonoperatively. J. Urol. 164, 1101-1105 (2000).

11. McLellan, D. L. et al. Rate and predictors of spontaneous resolution of prenatally diagnosed primary nonrefluxing megaureter. J. Urol. 168, 2177-2180 (2002).

12. Shukla, A. R. et al. Prenatally detected primary megaureter: a role for extended followup. J. Urol. 73, 1353-1356 (2005).

13. Shankar, K. R., Vishwanath, N. \& Rickwood, A. M. Outcome of patients with prenatally detected duplex system ureterocele; natural history of those managed expectantly. J. Urol. 165, 1226-1228 (2001).

14. Beetz, R. May we go on with antibacterial prophylaxis for urinary tract infections? Pediatr. Nephrol. 21, 5-13 (2006).

15. Mattoo, T. K. Evidence for and against urinary prophylaxis in vesicoureteral reflux. Pediatr. Nephrol. 25, 2379-2382 (2010).

16. Skoog, S. J. \& Steinhardt, G. Prophylaxis versus no prophylaxis for reflux. J. Urol. 187 , 1161-1163 (2012).

17. Subcommittee on Urinary Tract Infection, Steering Committee on Quality Improvement and Management. Urinary tract infection: clinical practice guideline for the diagnosis and management of the initial UTI in febrile infants and children 2 to 24 months. Pediatrics 128 , 595-610 (2011)

18. Song, S. H., Lee, S. B., Park, Y. S. \& Kim, K. S. Is antibiotic prophylaxis necessary in infants with obstructive hydronephrosis? J. Urol. 177, 1098-1101 (2007).
19. Lee, J. H. et al. Nonrefluxing neonata hydronephrosis and the risk of urinary tract infection. J. Urol. 179, 1524-1528 (2008).

20. Roth, C. C. et al. Occurrence of urinary tract infection in children with significant upper urinary tract obstruction. Urology 73, 74-78 (2009).

21. Coelho, G. M. et al. Risk factors for urinary tract infection in children with prenatal renal pelvic dilatation. J. Urol. 179, 284-289 (2008).

22. Islek, A., Güven, A. G., Koyun, M., Akman, S. \& Alimoglu, E. Probability of urinary tract infection in infants with ureteropelvic junction obstruction: is antibacterial prophylaxis really needed? Pediatr. Nephrol. 26, 1837-1841 (2011).

23. Faust, W. C. \& Pohl, H. G. Role of prophylaxis in vesicoureteral reflux. Curr. Opin. Urol. 17, 252-256 (2007).

24. Koyle, M. A. \& Caldamone, A. A. Part 4: considerations regarding the medical management of VUR: what have we really learned? Curr. Med. Res. Opin. 23 (Suppl. 4), S21-S25 (2007).

25. Ismaili, K. et al. Current management of infants with fetal renal pelvis dilation: a survey by French-speaking pediatric nephrologists and urologists. Pediatr. Nephrol. 19, 966-971 (2004).

26. Merguerian, P. A., Herz, D., McQuiston, L. \& Van Bibber, M. Variation among pediatric urologists and across 2 continents in antibiotic prophylaxis and evaluation for prenatally detected hydronephrosis: a survey of American and European pediatric urologists. J. Urol. 184, 1710-1715 (2010)

27. Yerkes, E. B., Adams, M. C., Pope, J. C. $4^{\text {th }}$ \& Brock, J. W. $3^{\text {rd }}$. Does every patient with prenatal hydronephrosis need voiding cystourethrography? J. Urol. 162, 1218-1220 (1999).

28. Lidefelt, K. J. \& Herthelius, M. Antenatal hydronephrosis: infants with minor postnatal dilatation do not need prophylaxis. Pediatr. Nephrol. 23, 2021-2024 (2008).

29. Mamì, C. et al. Outcome and management of isolated moderate renal pelvis dilatation detected at postnatal screening. Pediatr. Nephrol. 24, 2005-2008 (2009).

30. Yiee, J. H., Tasian, G. E. \& Copp, H. L. Management trends in prenatally detected hydronephrosis: national survey of pediatrician practice patterns and antibiotic use. Urology 78 , 895-901 (2011).

31. Palmer, L. S., Maizels, M., Cartwright, P. C., Fernbach, S. K. \& Conway, J. J. Surgery versus observation for managing obstructive grade 3 to 4 unilateral hydronephrosis: a report from the Society for Fetal Urology. J. Urol. 159, 222-228 (1998).

32. Chertin, B. et al. Does early detection of ureteropelvic junction obstruction improve surgical outcome in terms of renal function? J. Urol. 162, 1037-1040 (1999).

33. Shokeir, A. A. \& Nijman, R. J. Primary megaureter: current trends in diagnosis and treatment. BJU Int. 86, 861-868 (2000).

34. Chertin, B. et al. Long-term follow up of antenatally diagnosed megaureters. J. Pediatr. Urol. 4, 188-191 (2008).

35. Merlini, E. \& Lelli Chiesa, P. Obstructive ureterocele-an ongoing challenge. World J. Urol. 22, 107-114 (2004).

36. Merguerian, P. A., Taenzer, A., Knoerlein, K., McQuiston, L. \& Herz, D. Variation in management of duplex system intravesical ureteroceles: a survey of pediatric urologists. J. Urol. 184, 1625-1630 (2010).
37. Merguerian, P. A., Byun, E. \& Chang, B. Lower urinary tract reconstruction for duplicated renal units with ureterocele. Is excision of the ureterocele with reconstruction of the bladder base necessary? J. Urol. 170, 1510-1513 (2003).

38. Coplen, D. E. \& Austin, P. F. Outcome analysis of prenatally detected ureteroceles associated with multicystic dysplasia. J. Urol. 172, 1637-1639 (2004).

39. Han, M. Y. et al. Indications for nonoperative management of ureteroceles. J. Urol. 174, 1652-1655 (2005).

40. Direnna, T. \& Leonard, M. P. Watchful waiting for prenatally detected ureteroceles. J. Urol. 175 , 1493-1495 (2006).

41. Castagnetti, M. \& El-Ghoneimi, A. Management of duplex system ureteroceles in neonates and infants. Nat. Rev. Urol. 6, 307-315 (2009).

42. Besson, R., Ngoc, B. T., Laboure, S. \& Debeugny, $P$. Incidence of urinary tract infection in neonates with antenatally diagnosed ureteroceles. Eur. J. Pediatr. Surg. 10, 111-113 (2000).

43. Decter, R. M., Sprunger, J. K. \& Holland, R. J. Can a single individualized procedure predictably resolve all the problematic aspects of the pediatric ureterocele? J. Urol. 165, 2308-2310 (2001).

44. Husmann, D. A., Ewalt, D. H., Glenski, W. J. \& Bernier, P. A. Ureterocele associated with ureteral duplication and a nonfunctioning upper pole segment: management by partial nephroureterectomy alone. J. Urol. 154, 723-726 (1995).

45. Shekarriz, B., Upadhyay, J., Fleming, P., González, R. \& Barthold, J. S. Long-term outcome based on the initial surgical approach to ureterocele. J. Urol. 162, 1072-1076 (1999).

46. Upadhyay, J. et al. Impact of prenatal diagnosis on the morbidity associated with ureterocele management. J. Urol. 167, 2560-2565 (2002).

47. Chertin, B. et al. Does prenatal diagnosis influence the morbidity associated with left in situ nonfunctioning or poorly functioning renal moiety after endoscopic puncture of ureterocele? J. Urol. 173, 1349-1352 (2005).

48. Husmann, D. A., Strand, W. R., Ewalt, D. H., Kramer, S. A. Is endoscopic decompression of the neonatal extravesical upper pole ureterocele necessary for prevention of urinary tract infections or bladder neck obstruction? J. Urol. 167, 1440-1442 (2002).

49. Mamì, C. et al. Outcome and management of isolated severe renal pelvis dilatation detected at postnatal screening. Pediatr. Nephrol. 25, 2093-2097 (2010).

50. Uhari, M., Nuutinen, M. \& Turtinen, J. Adverse reactions in children during long-term antimicrobial therapy. Pediatr. Infect. Dis. J. 15, 404-408 (1996).

51. Allen, U. D., MacDonald, N., Fuite, L., Chan, F. \& Stephens, D. Risk factors for resistance to "first-line" antimicrobials among urinary tract isolates of Escherichia coli in children. CMAJ 160, 1436-1440 (1999)

52. Panaretto, K. et al. Risk factors for recurrent urinary tract infections in preschool children. J. Paediatr. Child. Health. 35, 454-459 (1999).

53. Hensle, T. W., Hyun, G., Grogg, A. L. \& Eaddy, M. Part 2: examining pediatric vesicoureteral reflux: a real-world evaluation of treatment patterns and outcomes. Curr. Med. Res. Opin. 23 (Suppl. 4), S7-S13 (2007).

54. Stenberg, A., Hensle, T. W. \& Läckgren, G. Vesicoureteral reflux: a new treatment algorithm. Curr. Urol. Rep. 3, 107-114 (2002). 
55. Wandstrat, T. L. \& Kaplan, B.

Pharmacoeconomic impact of factors affecting compliance with antibiotic

regimens in the treatment of acute otitis media.

Pediatr. Infect. Dis. J. 16 (2 Suppl.), S27-S29

(1997).
56. Johnson, C. C. et al. Antibiotic exposure in early infancy and risk for childhood atopy. J. Allergy Clin. Immunol. 115, 1218-1224 (2005).

57. Martinez, F. D. \& Holt, P. G. Role of microbial burden in aetiology of allergy and asthma. Lancet 354 (Suppl. 2), SII12-15 (1999).

\section{Author contributions}

M. Castagnetti researched the data for and wrote the article. M. Castagnetti and W. Rigamonti contributed to discussions of content. All authors reviewed and edited the manuscript before submission. 